\title{
Ansys CFX numerical study of stages centrifugal compressor with low-flow rate coefficient
}

\author{
Aleksey Yablokov ${ }^{1, *}$, Ivan Yanin ${ }^{1}$, Aleksey Danilishin ${ }^{1}$, and Anatoliy Zuev ${ }^{1}$ \\ ${ }^{1}$ Peter the Great St. Petersburg Polytechnic University, Polytechnicheskaya 29, St. Petersburg, \\ 195251, Russian Federation
}

\begin{abstract}
The article presents results of applying the methods of computational fluid dynamics for model low-flow rate stages of centrifugal compressors with flow rate coefficient $\mathrm{F}=0.028$. The computational domain of a model centrifugal compressor for CFD-simulation consists of the following elements: inlet chamber, impeller, vaneless diffuser, return channel, outlet chamber, shaft seal labyrinth, front and back shroud leakage. Full-scale experimental studies were conducted to model stage 028 in air at an inlet pressure of $\mathrm{p}^{*}=1 \mathrm{~atm}$. Numerical research for stage 028 held with flow rate coefficient $\mathrm{F}=(0.019-0.046)$ for three variants trailing edge of the impeller. According to the results of numerical research are constructed performances of stages centrifugal compressor and conducted verification of results. Estimated discrepancy between the results of numerical researches on the model with shaft seal labyrinth and without shaft seal labyrinth.
\end{abstract}

\section{Introduction}

Centrifugal compressors have found the widest application in modern power engineering $[1,2,3,4,5,6,8,9]$. Centrifugal compressors are the main gas compression equipment in modern gas transmission networks. The networks of OAO "GAZPROM Transgaz St. Petersburg" [7] employ more than 192 heavy centrifugal compressors with a total approximately capacity 1795 MW. A significant amount of energy is required for the actuator of gas compressor unit (GCU). The direct way to reduce these costs is to increase the efficiency of compressors. High efficiency of industrial centrifugal compressors (ICC), which are part of the GCU, is determined by the degree of gas-dynamic perfection of the flowing part, namely by choosing the optimal shape of the flowing part for operating conditions. The gas-dynamic design of the ICC should correspond not only to high efficiency indices, but also to have a sufficiently wide area of stable operation, with a significant margin from the left boundary side of the characteristic, i.e. margin from surging $[10,11,12,13,14,15,16,17,18,19,20]$.

\footnotetext{
* Corresponding author: yablokovaleksey@ mail.ru
} 


\section{Methods}

The designer relies largely on the results of studies of model steps with the conditional flow coefficient $\Phi$, which is of interest to him. The coefficient $\Phi$ is determined by the formula $[1,2,3,4,5,6]$.

$$
\Phi=\frac{\bar{m}}{\rho_{i n}^{*}\left(\pi D_{2}^{2} / 4\right) U_{2}},
$$

where $\bar{m}$-mass flow, $\mathrm{kg} / \mathrm{s} ; \rho_{\text {in }}^{*}$ - inlet gas density, $\mathrm{kg} / \mathrm{m}^{3} ; D_{2}$ - outlet diameter of the impeller, $\mathrm{m} ; U_{2}$ - circumferential velocity on the diameter $D_{2} \mathrm{~m} / \mathrm{s}$;

The characteristics of the stage, such as the dependence of the polytropic head coefficient on the conditional flow coefficient $\psi_{p}=\mathrm{f}(\Phi)$, the dependence of the polytropic efficiency from the conditional flow coefficient $\eta_{p}=\mathrm{f}(\Phi)$, are based on the results of model tests of stages with a certain design coefficient of flow. Coefficients of head and usefulness are calculated by formulas $[1,7]$ :

$$
\begin{gathered}
\psi_{p}=\frac{h_{p}}{U_{2}^{2}} ; \\
\eta_{p}=\frac{h_{p}}{h_{i}-h_{\mathrm{d}}},
\end{gathered}
$$

where $h_{p}$ - polytropic head, $\mathrm{J} / \mathrm{kg} ; h_{i}$ - internal head, $\mathrm{J} / \mathrm{kg} ; h_{d}$ - dynamic head, $\mathrm{J} / \mathrm{kg}$; heads in $\mathrm{J} / \mathrm{kg}$ in the above expressions are determined by the following formulas $[1,7,8]$ :

$$
h_{p}=\frac{n}{n-1} R T_{0}\left[\left(\frac{p_{i}}{p_{0}}\right)^{\frac{n-1}{n}}-1\right],
$$

The exponent $n /(n-1)$ is determined by the formula:

$$
\frac{n}{n-1}=\lg \frac{p_{i}}{p_{0}} / \lg \frac{T_{i}}{T_{0}},
$$

Dynamic head $h_{d}, \mathrm{~J} / \mathrm{kg}$, is determined by the formula:

$$
h_{d}=\frac{c_{i}^{2}-c_{0}^{2}}{2},
$$

where $c_{i}$ and $c_{0}$ - velocity in the corresponding sections, $\mathrm{m} / \mathrm{s}$.

$$
h_{i}=h_{t}+h_{f r}+h_{l e},
$$

where $h_{t}$ - theoretical head, $\mathrm{J} / \mathrm{kg} ; h_{f r}$ - disk friction head, J/kg; $h_{l e}$ - leakage head $\mathrm{J} / \mathrm{kg}$.

A numerical experiment of this stage was performed on a model with three versions of the output edge of the impeller, as well as on a model with shaft seal labyrinth and without them. The technique for experimental data processing of the Department KViHT is used in the calculation of gas-dynamic parameters, equations of viscous gas motions are used in numerical calculations, averaged over Reynolds RANS and turbulence model SST [8], parietal function $y+$ value less than 5 . The solution used a second-order discretization scheme maximum value of residuals in calculation parameters: $10^{-5}$. All calculations were carried out for the angular sectors of the flowing part elements and in a stationary setting. 
The total number of elements is about 5 million. Figure 1 shows the versions of the impeller blade output edge [9].

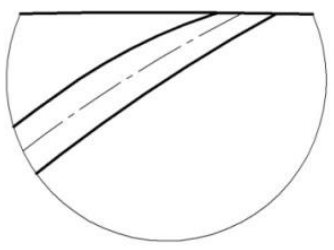

1

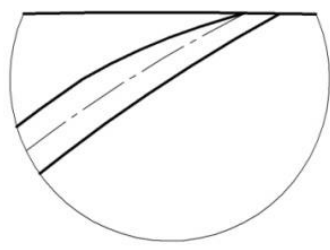

2

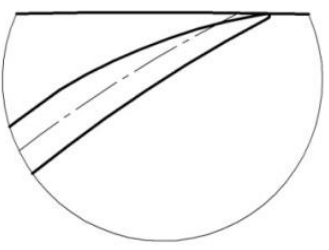

3

Fig. 1. Variations of the impeller blade output edge

1. Blade with blunt output edge

2. Blade pointed at front blade surface to middle line

3. Blade pointed at front blade surface to back surface

\section{Results}

Numerical modeling of viscous gas flow was carried out with three different versions of the impeller blade output edge.

The calculated characteristics and dependencies are constructed for all three variants. The results of numerical and model experiments for stage 028 with a blunt exit edge of the impeller blades are presented in Table 1.

Table 1. Comparison of model and numerical experiment data of centrifugal compressor stage 028 (blades with a blunt exit edge)

\begin{tabular}{|l|l|l|l|l|l|l|}
\hline & \multicolumn{2}{|l}{ Experiment } & \multicolumn{2}{l|}{ CFX calculation } \\
\hline$\Phi$ & $\Psi_{t}$ & $\psi_{i}$ & $\eta_{p}{ }^{*}$ & $\psi_{t}$ & $\psi_{i}$ & $\eta_{p}{ }^{*}$ \\
\hline 0.0474 & 0.354 & 0.364 & 0.325 & 0.43 & 0.44 & 0.414 \\
\hline 0.0427 & 0.438 & 0.451 & 0.625 & 0.50 & 0.51 & 0.597 \\
\hline 0.0372 & 0.502 & 0.52 & 0.767 & 0.61 & 0.63 & 0.750 \\
\hline 0.0329 & 0.551 & 0.573 & 0.801 & 0.63 & 0.65 & 0.796 \\
\hline 0.0271 & 0.597 & 0.625 & 0.798 & 0.64 & 0.67 & 0.768 \\
\hline 0.0202 & 0.651 & 0.693 & 0.760 & 0.65 & 0.70 & 0.709 \\
\hline
\end{tabular}

Figure 2 shows the gas dynamic characteristic of stage 028 for numerical and model tests (blades with a blunt exit edge). 


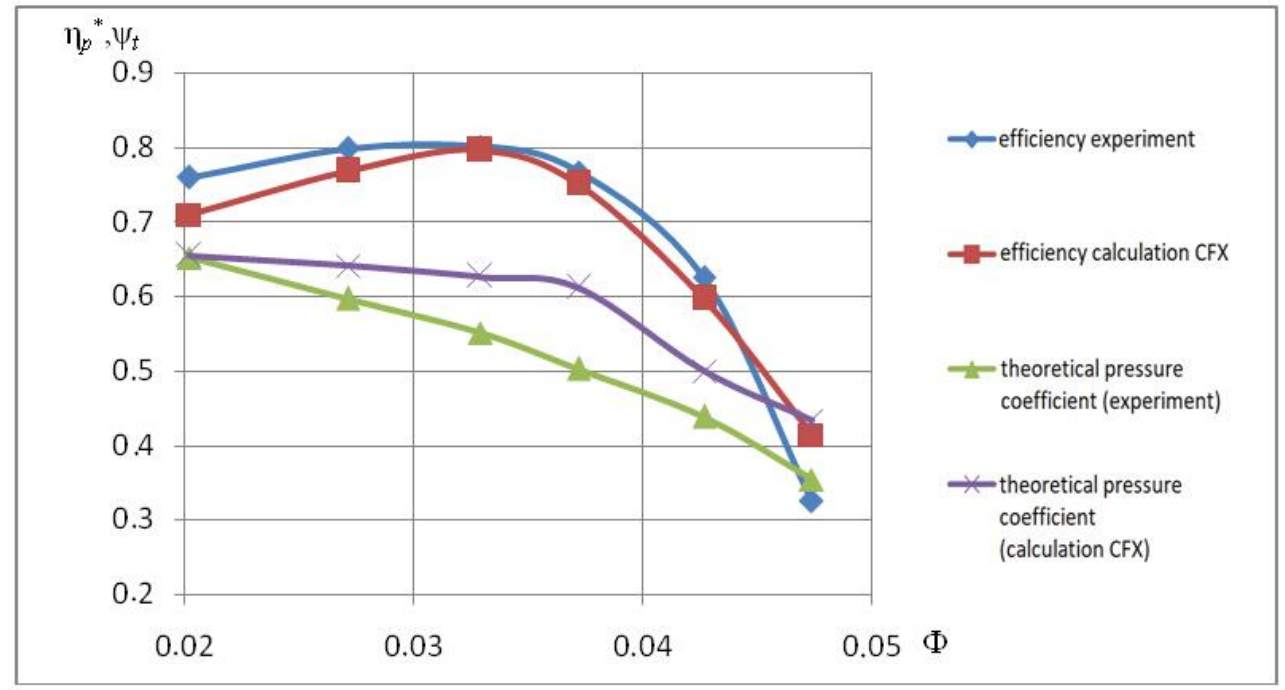

Fig. 2. Gas dynamic characteristic of stage 028 for numerical and model tests (blades with blunt output edge)

Table 2 presents the results of numerical and model experiments for stage 028 with impeller blades pointed at the front surface to the midline.

Table 2. Data comparison of the model and numerical experiments of stage 028 of the centrifugal compressor (the impeller blades are pointed along the front surface to the midline)

\begin{tabular}{|c|c|c|c|c|c|c|}
\hline \multirow[b]{2}{*}{$\Phi$} & \multicolumn{3}{|c|}{ Experiment } & \multicolumn{3}{|c|}{ CFX calculation } \\
\hline & $\Psi_{t}$ & $\psi_{i}$ & $\eta_{p}^{*}$ & $\psi_{t}$ & $\psi_{i}$ & $\eta_{p}{ }^{*}$ \\
\hline 0.0468 & 0.333 & 0.342 & 0.342 & 0.343 & $0 ., 353$ & 0.446 \\
\hline 0.0423 & 0.404 & 0.416 & 0.631 & 0.424 & 0.438 & 0.686 \\
\hline 0.0377 & 0.463 & 0.479 & 0.756 & 0.459 & 0.475 & 0.818 \\
\hline 0.032 & 0.522 & 0.55 & 0.79 & 0.548 & 0.570 & 0.805 \\
\hline 0.0283 & 0.574 & 0.6 & 0.795 & 0.587 & 0.614 & 0.786 \\
\hline 0.0202 & 0.625 & 0.665 & 0.754 & 0.669 & 0.712 & 0.714 \\
\hline
\end{tabular}

Figure 3 shows the gas dynamic characteristic of stage 028 for numerical and model tests (the impeller blades are pointed along the front surface to the middle line) 


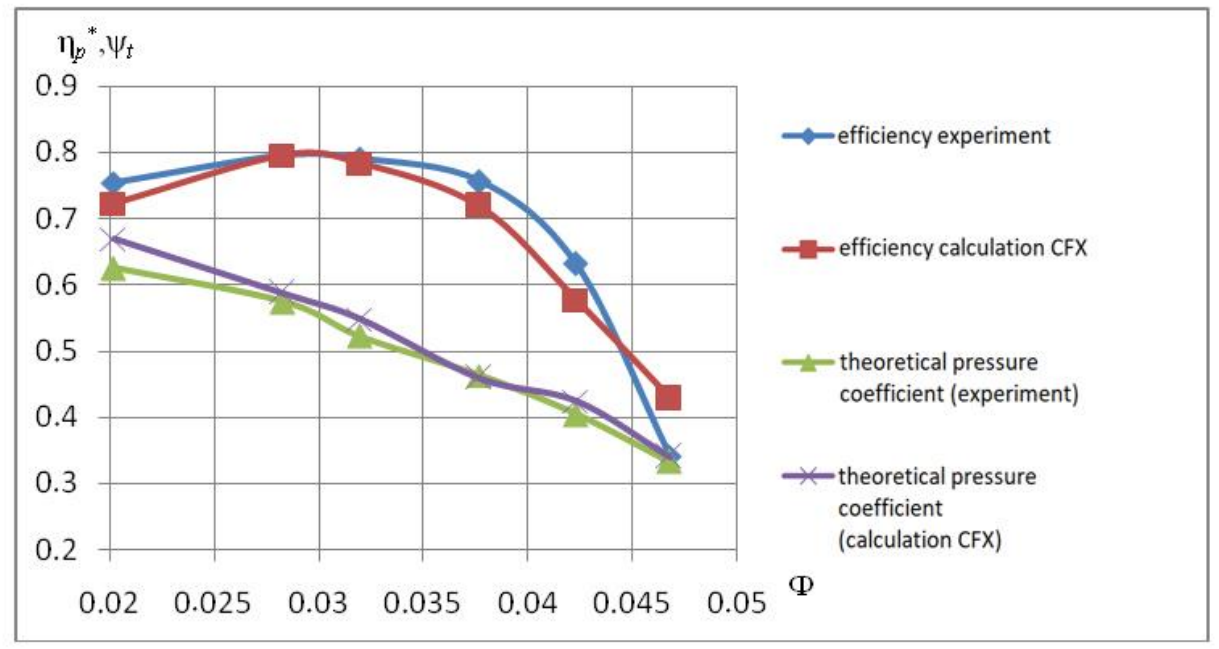

Fig. 3. Gas dynamic characteristic of stage 028 for numerical and model tests (impeller blades are pointed along the front surface to the middle line)

Table 3 presents the results of numerical and model experiments for stage 028 with impeller blades pointed at the front surface to the rear.

Table 3. Comparison of data from model and numerical experiments 026 (impeller blades are pointed along the front surface to the rear surface)

\begin{tabular}{|l|l|l|l|l|l|l|}
\hline & \multicolumn{3}{|l|}{} & \multicolumn{2}{l|}{ CFX calculation } \\
\hline$\Phi$ & $\Psi_{t}$ & $\psi_{i}$ & $\eta_{p}{ }^{*}$ & $\psi_{t}$ & $\psi_{i}$ & $\eta_{p}{ }^{*}$ \\
\hline 0.0457 & 0.352 & 0.362 & 0.402 & 0.340 & 0.350 & 0.427 \\
\hline 0.0413 & 0.427 & 0.44 & 0.654 & 0.443 & 0.457 & 0.673 \\
\hline 0.0373 & 0.483 & 0.5 & 0.774 & 0.512 & 0.530 & 0.781 \\
\hline 0.0326 & 0.539 & 0.56 & 0.809 & 0.560 & 0.583 & 0.803 \\
\hline 0.0258 & 0.603 & 0.633 & 0.8 & 0.624 & 0.656 & 0.797 \\
\hline 0.0187 & 0.66 & 0.706 & 0.742 & 0.665 & 0.711 & 0.742 \\
\hline
\end{tabular}

Figure 4 shows the gas dynamic characteristic of the stage 028 for numerical and model tests (the impeller blades are pointed along the front surface to the rear surface) 


\section{EECE-2018}

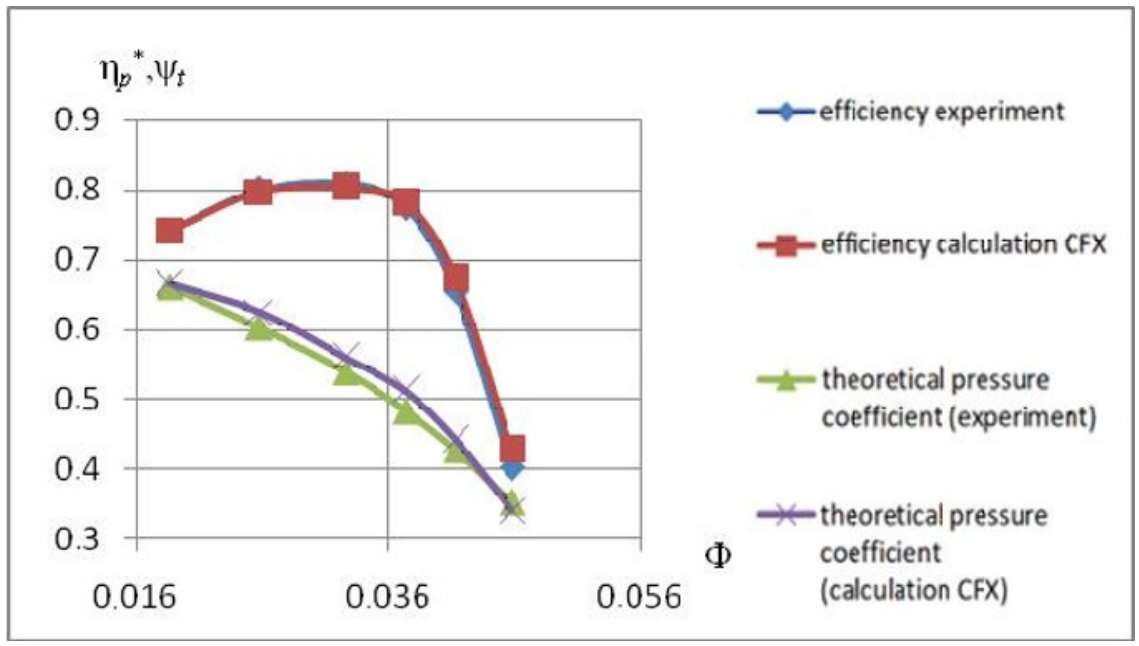

Fig. 4. Gas dynamic characteristic of stage 028 of the Central Committee for numerical and model tests (impeller blades are pointed along the front surface to the rear surface).

Second computer model maximally repeats the flowing part of the model stage. For each of the labyrinth seals, a separate geometric computer model has been created, exactly repeating the labyrinth seals at the model stage. On the model of labyrinth seals, a structured computational grid is created.

Two models of labyrinth seals are considered. The first labyrinth seal on the cover disk with four scallops, the number of elements of the grid is $5.7 \cdot 10^{5}$. The second labyrinth seal along the shaft of the machine with 18 combs and the number of elements of the grid is $8.8 \cdot 10^{5}$. The value of the parietal function $y+$ for the computed grids of the labyrinth seals does not exceed 3 . The calculated region of the flowing part of the stage is designed with the possibility of connecting models of labyrinth seals.

Table 4 presents the results of numerical and model experiments for stage 028 with impeller blades, sharpened along the front surface to the midline and labyrinth seals.

Table 4. Comparison of model and numerical experiment data of stage 028 of a centrifugal compressor (model with labyrinth seals, impeller blades pointed at the front surface to the midline)

\begin{tabular}{|l|l|l|l|l|l|l|}
\hline & \multicolumn{3}{|l}{ Experiment } & \multicolumn{3}{l|}{ CFX Calculation } \\
\hline$\Phi$ & $\psi_{t}$ & $\psi_{i}$ & $\eta_{p}{ }^{*}$ & $\psi_{t}$ & $\psi_{i}$ & $\eta_{p}{ }^{*}$ \\
\hline 0.0457 & 0.333 & 0.342 & 0.342 & 0.349 & 0.359 & 0.372 \\
\hline 0.0413 & 0.404 & 0.416 & 0.631 & 0.416 & 0.429 & 0.640 \\
\hline 0.0373 & 0.463 & 0.479 & 0.756 & 0.482 & 0.499 & 0.755 \\
\hline 0.0326 & 0.522 & 0.55 & 0.79 & 0.549 & 0.571 & 0.782 \\
\hline 0.0258 & 0.574 & 0.6 & 0.795 & 0.595 & 0.623 & 0.787 \\
\hline 0.0187 & 0.625 & 0.665 & 0.754 & 0.657 & 0.699 & 0.736 \\
\hline
\end{tabular}

Figure 5 shows the gas dynamic characteristic of stage 028 for numerical and model tests (impeller blades are pointed along the front surface to the center line, model with labyrinth seals) 


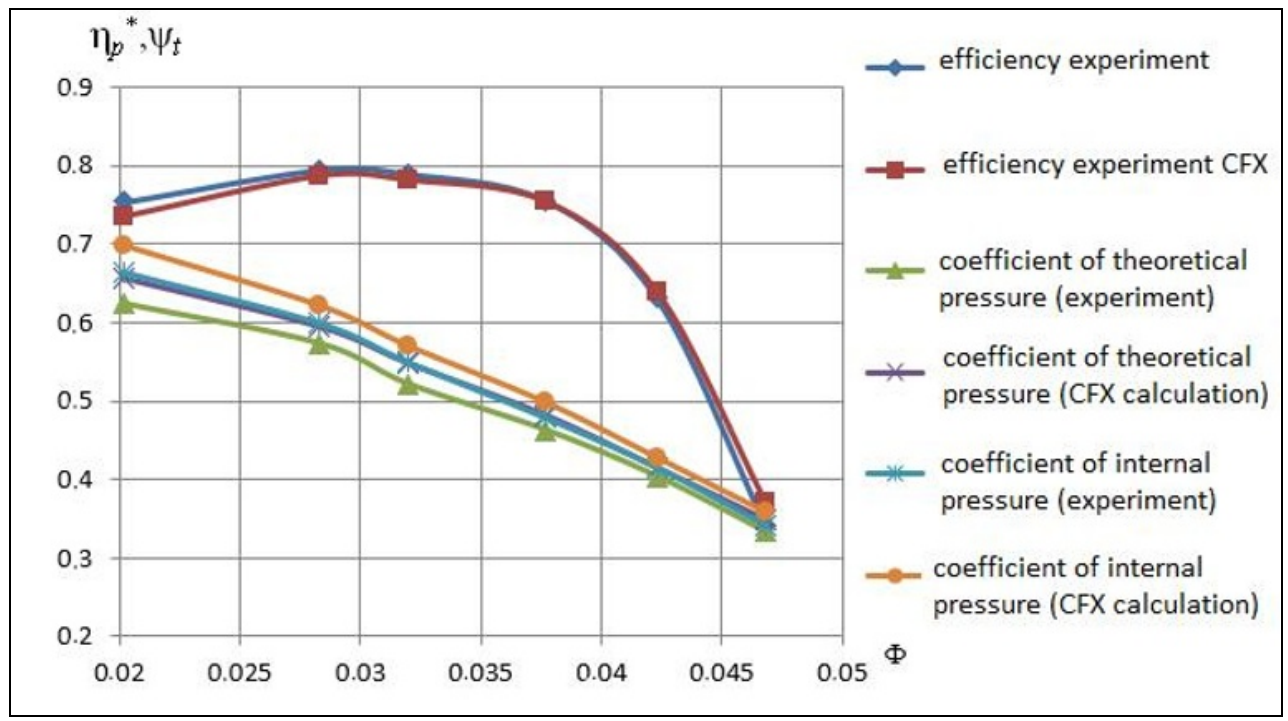

Fig. 5. Gas dynamic characteristic of stage 028 of the Central Committee for numerical and model tests (impeller blades are pointed along the front surface to center line, model with labyrinth seals)

\section{Discussion}

As a result of the validation of the numerical study in the CFD for this type of stage and its operation modes it was shown that for low-flow centrifugal compressor stages of intermediate type, the formulation of the problem, taking into account labyrinth seals and gaps with the number of elements of a structured grid of $4.5 \cdot 10^{6}$ and sectoral model, the discrepancy between numerical calculations and experimental data on pressure and temperature differ by no more than 5-8\%. This deviation satisfies the engineering accuracy according to ISO 5389 and allows talking about transferring the results of calculation and experimental research obtained for the model to the real sample of the PCC.

Numerical calculation of the three versions of the output edge of the blades of the impeller showed a qualitative and quantitative result corresponding to the model tests (within the permissible error) and theoretical concepts of the flow pattern in the flowing part of the PCC. Thus, with a decrease in the output angle of the blade, an insignificant decrease in the head developed by the impeller was observed, which is confirmed by the practice of compressor construction [1].

Considering the results of a numerical experiment on the second version of the impeller (the impeller blades are pointed along the front surface to the midline) with the seal model and without them, it is obvious that taking into account labyrinth seals has a positive effect on the accuracy of the solution. The discrepancy between the results of numerical calculations and the results of model tests with allowance for overflows through labyrinth seals was reduced to $3 \%$, for a total pressure behind the impeller at the rated operating mode of the stage, the divergence was $2 \%$; in the modes of the least mass flow, the divergence of the calculation with the experimental data is $5 \%$. However, the introduction of the model of labyrinth seals leads to an increase in the number of cells in the computational grid by approximately 1.2-1.5 times and additional boundary conditions, which undoubtedly leads to an increase in the calculation time. 
As a result of a numerical study, the authors made conclusions about the need to take into account the flows through the labyrinth seals when performing optimization calculations.

\section{References}

1. Y.B. Galerkin, Proceedings of the scientific school of compressor engineering SPbGPU, 100-300 (2010)

2. Y.B. Galerkin, Y.V. Kozhukhov, Kompressornaya tekhnika i pnevmatika, 7, 13-18 (2005)

3. Y.B. Galerkin, Y.V. Kozhukhov, Kompressornaya tekhnika i pnevmatika, 4, 32-37 (2007)

4. Y.B. Galerkin, Y.V. Kozhukhov A.M. Yablokov, Proceedings of XLI Science Week STU: materials of scientific-practical conference with international participation, St. Petersburg, Russian Federation, 98 (2012)

5. Y.V. Kozhukhov, I.A. Tuchina, Calculation of two-tier stage centrifugal compressor: $a$ tutorial, St. Petersburg, (2014)

6. Y.V. Kozhukhov, A.M. Yablokov, International Technology Forum "Innovations. Technologies. Manufacturing": Proceedings of the scientific conference dedicated to the 100th anniversary of the chief designer P.A. Kolesov, 88 (2015)

7. GAZPROM transgaz Sankt-Peterburg, Available: URL: http://spb-tr.gazprom.ru/about/ (Accessed 26.10.2015)

8. D.M. Gamburger, Numerical simulation of viscous flow in a centrifugal compressor stage: methodology and results: dissertation, 2009

9. A.M. Yablokov, Numerical simulation of viscous flow in the model low-flow rate stage centrifugal compressor with a nominal flow coefficient 0.028 dissertation (2013)

10. J. Galiando, S. Hoyas, P. Fajardo, R. Navarro, Engineering Applications of Computational Fluid Mechanics, 7, 441-460 (2013)

11. M. Elfert, A. Weber, D. Wittrock, A. Peters, C. Voss, E. Nicke, J. Turbomach., 139(10) (2017)

12. T. Wang, C. Peng, J. Wu, MECHANIKA, 20(4), 402-406 (2014)

13. C. Xu, R.S. Amano, International Journal of Rotating Machinery, 11 (2012)

14. C. Xu, M. Muller, International Journal of Rotating Machinery, 3, 190-196 (2005)

15. W. Jansen, A.M. Kirschner, Impeller blade design method for centrifugal compressors (NASASP304, Part II, 1974)

16. Y.I. Biba, D.A. Nye, L.I.U. Zheji, International Journal of Rotating Machinery, 8, 309317 (2002)

17. H. Krain, B. Hoffmann, Proceedings of the ASME Fluids Engineering Division Summer Meeting (1998)

18. T. Sato, J.M. Oh, A. Engeda, Proceedings of the Institution of Mechanical Engineers $C$, 10, 1053-1059 (2005)

19. A.A. Aksenov, A.M. Danilishin, Y.V. Kozhukhov, A.M. Simonov, AIP Conference Proceedings 2007 (2018)

20. Y. Boldyrev, A. Rubtsov, Y. Kozhukhov, A. Lebedev, I. Cheglakov, A. Danilishin, CEUR Workshop Proceedings, 273-279 (2015) 